\title{
Reducing Waste: Repair, Recondition, Remanufacture or Recycle?
}

\author{
Dr. Andrew M King* \\ Dr. Stuart C Burgess \\ Department of Mechanical Engineering \\ University of Bristol \\ Bristol, BS8 1TR \\ United Kingdom
}

\author{
Dr. Winnie Ijomah \\ Mr. Chris A McMahon \\ Dept of Mechanical Engineering \\ University of Bath \\ Bath, BA2 7AY \\ United Kingdom
}

\begin{abstract}
Between 1980 and 1997, municipal waste in OECD countries increased by around 40\%. This paper outlines the very real negative effects of this increase and then introduces the two main European Union policies that have been established to address this problem: a landfill directive and legislation on extended producer responsibility (EPR).
\end{abstract}

The paper then describes and then compares the four alternative strategies to reducing end-oflife waste within the context of extended producer responsibility: namely repairing, reconditioning, remanufacturing or recycling. It also introduces a more robust definition of remanufacturing, validated by earlier research, which differentiates if from repair and reconditioning.

From a consideration of the different factors involved, it concludes that remanufacturing may well be the best strategy. This is because it enables the embodied energy of virgin production to be maintained, preserves the intrinsic "added value" of the product for the manufacturer and enables the resultant products to be sold "as new" with updated features if necessary. 


\section{The Context}

\subsection{The waste problem}

Between 1980 and 1997, municipal waste in OECD countries increased by around 40\%. Perhaps most alarmingly, it is predicted to grow by a further $40 \%$ by 2020 (OECD, 2001).

Increased economic growth has been the principal cause for this increase in waste production: economic growth increases production, which increases consumption and thus increases waste. The environmental pressure from this increase in waste generation is threefold:

1. Firstly it results in the permanent loss of material and energy resources. The potential loss of resource from electrical and electronic waste in Europe has been estimated to include 2.4 million tonnes of ferrous metals, 1.2 million tonnes of plastics and 0.65 million tonnes of copper (AEA Technology, 1997). However, whilst it is widely agreed that natural resources will become more expensive due to the need for new excavation/processing technologies, there is little evidence that they are actually close to running out (Tilton, 2003).

2. Secondly, as the current landfill sites are filling up, this leads to pressure to use new sites with the loss of that land use for housing, leisure or agriculture. In England, of the 28.8 million tonnes of municipal waste produced in 2001/2 a higher proportion of $77 \%$ went to landfill sites (DEFRA, 2003a). A recent report has estimated that there is only 6.5 years of remaining landfill site space left in the UK (Biffa, 2002). In addition, research has established that house prices decrease near landfill sites making such sites undesirable in the urban areas where they are most needed (DEFRA, 2003b).

3. And thirdly, the additional waste left in these landfill sites increases air, water and land pollution. For example, within OECD countries between $25-50 \%$ of contaminated areas are as a result of waste activities and 34\% of methane emission (one of the 6 greenhouse gases targeted for reduction in the Kyoto Protocol) comes from landfill sites. 


\subsection{The policy solution}

In the early 1990s some European Union member states, notably the Netherlands, Germany and Sweden developed their own national policy measures to deal with their growing waste problems. However, in order to provide a workable single market throughout the EU (such that production and trade measures were harmonised), these policy measures needed to be extended to all member states (Cooper, 2000). The European Union has responded by introducing two major policies: a landfill directive and legislation on extended producer responsibility (EPR).

Under the EU Landfill Directive (EU, 1999) the UK Government is obliged both to closely regulate the issuing of permits for new landfill sites (with the aim of ensuring that better operating standards are in place) and to reduce landfill municipal waste to $33 \%$ of its 1995 level by 2020 (principally because the amount of suitable space is running out).

One mechanism to achieve this has been a landfill tax - presently charged at $£ 13$ per tonne of waste although set to increase to a long-term rate of $£ 35 /$ tonne (HM Treasury, 2002). In addition, the UK Government's Waste Strategy 2000 for England and Wales (DETR, 2000) has four levels - in order of preference - being:

1. waste reduction (such as extending product durability),

2. waste re-use (such as remanufacturing products for a second life),

3. waste recovery (such as raw material recycling), and lastly

4. waste landfill (as the last resort).

Extended Producer Responsibility (EPR) is defined by the OECD as "the principle that manufacturer and importers of products should bear a significant degree of responsibility for the environmental impacts of their products throughout the product life-cycle, including impacts from the selection of materials, the production process, and from the use and disposal of the products at the end of life cycle" (OECD, 2001). EPR is the logical extension of the "polluter 
pays" principle. This rests on the argument that environmental impacts are substantially determined at the point of design where key choices are made - on materials, processing and finishing technology etc - that is, with the producer (Gertsakis et al., 2000).

This principle has been most clearly implemented in the WEEE Directive on Waste Electrical \& Electronic Equipment. In August 2004, EU OEM (Original Equipment Manufacturers) and importers will be legally bound to take significant responsibility for the treatment and disposal of post-consumer products (EU, 2003). Electronic and electrical waste contains substances that may have a damaging impact on the environment when it is disposed of either in landfill sites or by incineration. In addition, the volume of electronic and electrical waste is growing by between 3 to $5 \%$ a year - about three times faster than general waste (ICER, 2000). Electrical and electronic waste is defined as all appliances run by electricity, which does not exceed 1,000 volts for AC and 1,500 volts for DC. Products operating at higher voltages are excluded because their high value makes them unlikely to end up in the waste stream. The objectives of the WEEE Directive include:

1. reducing the waste arising from end-of-life electrical and electronic equipment (EEE),

2. improving and maximising recycling, re-use and other forms of recovery of wastes from end-of-life electrical and electronic equipment, and

3. minimising the impact on the environment from their treatment and disposal.

A recent analysis on the likely effect of the WEEE Directive in the UK concludes that it may only reduce Municipal Solid Waste (MSW) by $0.1 \%$ because high levels of WEEE waste is already recycled (PriceWaterhouseCoopers, 2002). But this overlooks the fact that end-of-life waste also generates commercial waste during the production phase for the electrical product. One rule-of-thumb cited is that every tonne of consumer waste has also generated 5 tonnes of manufacturing waste and 20 tonnes of resource extraction waste (Meadows D H et al, 1992). Thus, if the WEEE Directive were to lead to an increase in product repair and remanufacture, 
this would in turn reduce both consumer, manufacturing and resource extraction waste. However, regardless of the quantified difference in waste, an undisputed effect of the Directive will be to transfer the cost of waste management from the general taxpayer to the individual OEMs.

Although the Directive gives 11 categories of electronic and electrical waste, a recent study of present waste levels found that large household appliances (such as fridges, cookers and washing machines) and IT equipment (such as PCs, mainframes, printers, copiers) accounted for $43 \%$ and 39\% respectively (ICER, 2000). The study also found that whilst $88 \%$ of large household appliances were recycled, only $40 \%$ (approximately) of IT equipment is currently recycled. The principle reasons given for this difference were firstly that it is easier to separate large appliances in the waste stream and secondly that it is harder to separate out the ferrous metal from IT equipment.

\section{The practical solutions}

In order to achieve a step change in practice, designers need to consider the entire "lifecycle" of a product from raw material extraction, through manufacturing, product use and final disposal. And from doing this, a key concept to true sustainability is identified as "closed loop design" where disposal streams are diverted to become new raw material/manufacturing streams. This is illustrated in figure 1.

\section{Figure 1: Closed loop design through repair, remanufacturing or recycling}

There are only two possible long-term fates for waste materials: reuse (closed loop) or dissipative loss (open loop). This is a straightforward implication of the law of conservation of mass. Thus, a relatively simple proxy for "sustainability" in environmental terms is the ratio of recycled/reused material to the total supply of virgin and recycled/reused material (Ayres \& Simonis, 1993). 


\subsection{Repairing}

The most logical approach to closing the loop on product use is simply to repair and extend the product's life. However, whilst this is intrinsically a simple concept, its practise is low and little research has been undertaken to understand this closed loop option. Repairing is simply the correction of specified faults in a product. Generally, the quality of repaired products is inferior to those of remanufactured and reconditioned alternatives. When repaired products have warranties, they are less than those of newly manufactured equivalents. Also, the warranty may not cover the whole product but only the replaced component.

Empirical research has shown that appliance ownership within the UK increased by around $60 \%$ over a 5-year period (Cooper \& Mayers, 2000). In addition, consumer decisions during the 'use' phase of a product whether to repair, pass on or throw items away accordingly affect product life spans (and thus the rate of waste generation). The E-SCOPE survey found that $68 \%$ of respondents cited cost as a reason why they did not get items repaired; a factor borne out by the fact that whilst new washing machine prices increased by only $40 \%$ during the 1980s-1990s repair costs over this period increased by $165 \%$ (Consumers International, 1998). Throughout the UK, the sustained existence of jumble sales and charity shops show that there is a supply and demand for second hand goods (Cooper, 2002). However, by law they are not allowed to sell electronic equipment unless they have had it reconditioned.

Products go out of use for essentially two reasons: functional obsolescence (they physically fail and need repair) or fashion obsolescence (they loose their appeal due to new products appearing in the market with different/additional features). Planned obsolescence is one way in which capitalist markets generate a demand for new sales; B Earl Puckett, former head of Allied Stores Corporation said "We must accelerate obsolescence ... It is our job to make women unhappy with what they have ... We must make them so unhappy that their husbands can find no 
happiness or peace in their excessive savings (Packard, 1963). Indeed, a growing body of literature cites the fact that consumerism is the dominant social paradigm to be the fundamental cause of the world's sustainability problems (Halliday, 2002). This is seen to be encouraged by a culture of individualism and a relaxation in credit controls (Cooper, 1994). In contrast to this view, planned obsolescence (and the consumerism it generates) has been defended "as an engine of technological progress" (Fishman, Gandal \& Shy, 1993). Although flawed in terms of economic efficiency and environmental sustainability, the argument planned obsolescence this represents progress is often politically expedient (Cooper, 2002).

\subsection{Reconditioning}

Reconditioning involves less work content than remanufacturing, but more than that of repairing. This is because reconditioning usually requires the rebuilding of major components to a working condition that is generally expected to be inferior to that of the original model. All major components that have failed or that are on the point of failure will be rebuilt or replaced, even where the customer has not reported or noticed faults in those components. The fact that a reconditioned product is clearly not new (and thus not offering the latest functionality or aesthetic styling of new product) means that it has the same market acceptance issues to products that have been repaired.

This practice is well established and has created what is called a "grey goods" market where original "white goods" products such as fridges and washing machines are reconditioned after a single life and returned for sale as "grey goods". The visual image is clear that the product is not returned to its original condition but has been improved to allow extended functional use. Often such products are either sold directly to low-income families or indirectly through local government social service providers. The reduced quality of a reconditioned product allows it to be sold affordable to such social groups (Renew, 2004). Another example of reconditioning practice comes from a company named "181 Respin". This Plymouth based company 
reconditions components from white goods and sells them to service agents and reconditions whole products for sale to low-income families and landlords. In each case, the reconditioned products have a lower performance specification and associated warranty than the equivalent new product (DARP, 2003).

\subsection{Remanufacturing}

Remanufacturing is the only process where used products are brought at least to Original Equipment Manufacturer (OEM) performance specification from the customer's perspective and, at the same time, are given warranties that are equal to those of equivalent new products (Ijomah W, 2002). The reasoning here being that if a remanufactured product has quality equal to that of a new equivalent then its warranty must also be the same. Of all the current "secondary market" (used product) processes, remanufacturing involves the greatest degree of work content and as a result its products have superior quality and reliability. This is because remanufacturing requires the total dismantling of the product and the restoration and replacement of its components. Remanufacturing is particularly applicable to complex electromechanical and mechanical products which have cores that, when recovered, will have value added to them which is high relative both to their market value and to their original cost (Lund, $1985)$

The essential characteristic from an environmental aspect is that remanufacturing preserves the embodied energy (emergy) that has been used to shape the components for their first life. Lund estimates that a remanufactured product only requires $20-25 \%$ of the energy used in its initial formation (Lund, 1985). Thus, as well as reusing the material, the energy required to produce a new product is significantly lower. Although the environmental advantages are clear (and meet the requirements of extended producer responsibility legislation) there are other benefits from remanufacturing. Bras \& McIntosh (1999) state that, by receiving back old products, 
manufacturers can obtain feedback on reliability and durability information and can also resell into lower-priced markets, typically costing $60 \%$ of the original production cost.

Ijomah et al. (1998) describe current remanufacturing activity by the following activities:

1. Receive the "core", that is the parts of the product to be remanufactured. The term "core" is used, as typical remanufactured parts are larger core items of the product.

2. Strip and clean the core into individual elements. As the used parts may be dirty, they are dismantled and appropriately cleaned. A visual inspection would discard badly damaged elements.

3. Estimate \& quote remanufacturing costs. As many remanufacturing companies are subcontractors to the OEMs, the cost of remanufacturing is often estimated on each product to determine the appropriate rectification strategy.

4. Remanufacture. If the component were suitable, the appropriate machining/fabrication processes would be used to remanufacture the component to an "as new" specification.

5. Build, test and dispatch. Finally, the remanufactured components are reassembled (together with necessary replacement components) to build the new product. After appropriate quality testing, the product would be dispatched for sale.

Arguably the most well known (and certainly the most referred to) example of remanufacturing is that of photocopiers made by Rank-Xerox; their process is shown in figure 2 (Xerox, 2003).

Figure 2: Xerox's equipment recovery \& parts reuse/recycle process (Xerox, 2003)

In 1987, Rank-Xerox started a new programmed called "asset recovery" and created a new, wholly owned subsidiary next to its manufacturing plant in The Netherlands. Its aim was twofold: firstly, to remove old copying machines from the waste stream and, secondly, to process these machines for resale. This was called the Asset Recovery Operation (ARO). In $19895 \%$ of scrapped machines were remanufactured; by 1997 this had risen to $75 \%$ of the 80,000 copiers 
returned. At the beginning of 1993 landfill accounted for $41 \%$ of manufacturing waste but by 1995 this was only $21 \%$. To encourage return, an incentive scheme was introduced in The Netherlands, and although the remanufactured copiers compete with new Xerox machines, the company claims to have saved $\$ 65$ million by 1996 (Ayres et al., 1997). The company now has remanufacturing facilities in the USA, the UK, The Netherlands, Australia, Mexico, Brazil and Japan (Kerr \& Ryan, 2001).

Aware of the growing interest in remanufacturing within the UK, Oakdene Hollins undertook a UK-wide survey of activities to better understand what current happens and identify issues for future development (Parker, 2003). Parker, after a review of academic work, includes questionnaire/interview evidence from 14 companies and identified three key parameters that influenced the activity: intrinsic value (the value of the product being remanufactured), recontructability (how easy it was to disassemble and the rebuild the product) and evolution rate (how quickly new product varies appeared on the market). The recommendations include changes to legislation to allow reused components in new products, further research to enable design for remanufacture and the development of product-service systems that include upgrade/maintenance with initial purchase.

\subsection{Recycling}

Recycling is "the series of activities by which discarded materials are collected, sorted, processed, and used in the production of new products" (NRC, 1999). According to the Northeast Recycling Council (NERC), recycling activity in New York in 1997 reduced energy use by $9 \%$, sulphur oxide emissions by $12 \%$ and saved 2.7 million tons of iron ore from needing to be extracted to form new materials (NERC, 1999). Thus, it is clear that it is environmentally better to recycle materials rather than take them to a landfill site. Indeed, for aluminium, the energy saving can be as high as $91 \%$ by recycling scrap compared with the process of using the primary raw material, bauxite (Ogilvie, 1992). 
However, although it is currently the most mature waste avoidance strategy, with established rates as high as $80 \%$ for certain products (ICER, 2000), many designers are reluctant to use recycled materials because of uncertain quality or supply standards (Chick \& Micklethwaite, 2002). One attempt to address the issue of quality has been to further define a recyclable material as one that can reacquire the material properties it had in its virgin state and thus to develop a measure of the "recyclability" of different materials by assessing virgin, scrap and processed economic values (Villalba et al, 2002).

In addition, whilst the materials recycled reduce virgin material use, they do still require additional energy to be used to reform them into manufactured products. Jacobs (1991) states "Wastes can't turn back into resources unless there is some external source of energy. 'Recycling' doesn't just happen on its own ... it has to be powered by an energy source. This is because the embodied energy (known as emergy) used in production is lost during the recycling process.

Figure 3 below presents the three operations of repair, reconditioning and remanufacturing on a hierarchy based on the work content that the typically require, the performance that should be obtained from them and the value of the warranty that they normally carry.

Figure 3: The hierarchy of secondary market production processes (Ijomah, 2002) 


\section{Discussion: which return loop is "best"?}

Returning to the idea of closing loops, Stahel (1994) states that the smaller the loop, as shown in figure 3, the more profitable it is. Thus, according to Stahel, repairing or remanufacturing products ought to be more common (if it is more profitable) than recycling. And yet, the reality is the opposite: recycling is far more common that repair or remanufacture.

Figure 4: Self-replenishing loops: $1=$ reuse, $2=$ repair, $3=$ remanufacture, $4=$ recycle

According to Stahel, the reason for this reality has been due to a lack of product lifetime liability. Until the recent introduction of extended producer responsibility legislation (such as the WEEE directive) a manufacturer had no liability (outside of a short warranty period) for the product sold. Therefore, as recycling is essentially disconnected from individual manufacturers (the material is mixed with other material and processed remotely), this has been the dominant return loop. In addition, some authors provocatively consider the availability of recycling to be a helpful excuse for businesses to justify short product lives because recycling is perceived as a good environmental practise (Fairlie, 1992).

Another way of understanding these issues is through the first two laws of thermodynamics. The first law states that no energy or material can either be created or destroyed, merely transformed. This promotes the idea of closed loops to transform material back into useful products rather than into useless (and harmful) waste. However, the second law of thermodynamics shows that this transforming process itself requires additional energy. The second law states that for a closed system the entropy (disorder) will always increase. The very waste problem is a manifestation of this fact: high-energy material comes in at the start and gradually becomes more disordered to the final state of waste. However, to change this, additional energy needs to be added to the system; and more energy needs to be added to higher 
entropy material. Thus, recycling (using highly disordered material) requires more "corrective" energy than remanufacturing (where the primary shape is preserved), which in turn requires more than reconditioning \& repair (where most material and assembly are kept). Therefore, Stahel's argument for smaller return loops is supported from a thermodynamic/energy viewpoint.

So, what will promote a move towards remanufacturing, reconditioning and/or repair? The answer is extended producer responsibility legislation. With the introduction of such legislation, manufacturers are now liable for their products through and beyond their end-of-use life. Whilst a strategy to ensure recycling would meet their obligations, many manufacturers see that this is an additional cost with little or no financial benefit (scrap values are often less than recycling costs). Thus, interest in repairing, reconditioning or remanufacturing products is increasing because the potential profits from these smaller loops will be the most "value adding" way to discharge extended producer responsibility. They also have the added societal benefits of providing gainful employment for low to medium skilled labour because much of their tasks are simple to learn.

Repair, recondition or remanufacture? In terms of environmental benefit, repair is clearly the better option because less energy is needed and virtually all material is kept. However, the barrier of consumer behaviour (and manufacturers' demand for future new sales) is huge. To change the present culture of fashion obsolescence driving new sales is a macro-level activity. A similar argument can be followed for reconditioning. However, if products can be remanufactured such that the second-life product is made up-to-date to the market, then this could be both economically viable to manufacturers (an essentially new product is made) and desirable to consumers. As shown earlier, remanufacturing could lead to lower waste levels and require less energy than recycling making it a micro-level solution to the growing waste problem. 
However, remanufacturing is presently not without significant barriers (King \& Burgess, 2004). Reverse logistics: returning end-of-life products to a small number of locations can be the biggest cost involved in remanufacturing. A variety of approaches are used to receive the old product including new product discounts, free postal return and voluntary sector partnerships with retail groups.

When end-of-life products arrive at a potential remanufacturing factory, a manufacturer needs to disassemble the product. This can be difficult and expensive and was found to be a fundamental barrier. A variety of approaches are used including part standardisation, reversible assembly methods and modular/platform design. Once the products/parts have been disassembled, the manufacturer needs to find out what condition the products/parts are in. If the parts are suitable for remanufacture they may go to one location; otherwise they would be sent for recycling or landfill. Approaches to deal with this include visual inspection and in-service monitoring (data collected during the use phase).

But clearly, the most fundamental barrier at present is the lack of a credible and stable demand for remanufactured products. This was seen to be the greatest policy barrier to initiate new remanufacturing schemes. One approach is to establish distinct brand selling lower price products, although the most common approach is to develop Product-Service-Systems (PSS). PSS involves providing customers with a service rather than a bought product such that it is leased or hired. Thus, manufacturers are able return used products for remanufacture and then reintroduce them into the market.

\section{Conclusion}

This paper has compared and contrasted four different waste avoidance strategies, namely: repairing, reconditioning, remanufacturing and recycling. Stahel's argument for smaller return loops has been discussed and supported from a thermodynamic/energy viewpoint. Thus, 
recycling (using highly disordered material) requires more "corrective" energy than remanufacturing (where the primary shape is preserved), which in turn requires more than reconditioning \& repair (where most material and assembly are kept).

However, although reconditioning \& repair require the least additional energy, the barrier of consumer behaviour (and manufacturers' demand for future new sales) is huge. Thus, the authors suggest that remanufacturing, returning products that can be an economically viable option (by allowing as-new products to be sold, possibly updated to suit new conditions) whilst simultaneously benefiting society (by providing low skill labour and reduced cost products for low income families) and the environment (by reducing landfill and limiting the loss of embodied energy).

\section{References}

AEA Technology (1997) Recovery of WEEE: Economic and Environmental Impacts, AEA Technology, Abingdon, Oxon. UK June 1997

Ayres R \& Simonis U (1993), Industrial Metabolism, University Press, Tokyo, Japan, 1993

Ayres R, Ferrer G \& Van Leynseele T (1997), Eco-Efficiency, Asset Recovery and Remanufacturing, European Management Journal, Vol. 15, No. 5, pp 557-574, 1997

Biffa (2002) Future Perfect, An analysis of Britain's waste production and disposal account, with implications for industry and government of the next twenty years, ISBN 0-952-3922-3-2, p44, www.biffa.co.uk [5 August 2003]

Bras B \& McIntosh M W (1999) Product, process and organizational design for remanufacture - an overview of research Robotics and Computer Integrated Manufacturing, Vol 15 (1999), pp 167-178.

Charter, M, Chick A (1997), Editorial, Journal of Sustainable Product Design, No 1, April 1997, pp 5-6

Chick, A. \& Micklethwaite, P (2002), Obstacles to UK Architects and Designers Specifying Recycled Products and Materials, Design History Society Conference, Aberystwyth

Cooper T, (1994) Beyond Recycling - The Longer life option. The New Economics Foundation, 1994 
Cooper T, (2000), WEEE, WEEE, WEEE, WEEE, all the way home? An evaluation of proposed electrical and electronic waste legislation, European Environment, 2000, Vol. 10, pp 121-139

Cooper T \& Mayers K (2000), Prospects for household appliances, E-SCOPE Survey, Centre for Sustainable Consumption, Sheffield Hallam University

Cooper T (2002), Attached to this World? Waste and "the most materialistic of the great religions" Consumption, Christianity and Creation, Seminar on $5^{\text {th }}$ July 2002, Centre for Sustainable Consumption, Sheffield Hallam University.

Consumers International (1998), Green guidance: how consumer organisations can give better advice on putting sustainable consumption into practice, Consumers International, ISBN 1-902391-09-8, pp 14-31

DARP (2003), DARP (Devon Appliance Recycling project) Environmental: WEEE Remarket Final Report, 2003 http://www.darpenvironmental.com/downloads/weeeremarketfinalreport.pdf [10 February 2004]

DEFRA (2003a), Municipal Waste Management Survey 2001/02, Summary

www.defra.gov.uk/environment/statistics/wastats/mwb0102/wbsummary.htm (visited 10th October 2003) DEFRA (2003b), Press Release: Living close to a landfill site cuts property values http://www.defra.gov.uk/news/2003/030221a.htm [10th October 2003]

DETR (2000), UK Government's Waste Strategy 2000 for England and Wales, http://www.defra.gov.uk/environment/waste/strategy/cm4693/index.htm [10th October 2003]

EU (1999), European Council directive 1999/31/EC on the landfill of waste, Official Journal L182, 16.7.1999, pp1-19

EU (2003), European Council directive 2002/96/EC on the landfill of waste, Official Journal L37/24, 13.2.2003, pp1-15

Fairlie, S (1992) 'Long Distance, Short Life: Why big business favours recycling', The Ecologist, Vol 22, No. 6, pp276-283

Fishman A, Gandal N \& Shy O (1993) Planned Obsolescence as an engine of technological progress, The Journal of Industrial Economics, 1993, Vol. 41, No. 4, pp 361-370

Gertsakis J, Morelli N \& Ryan C (1998), Return to sender: An introduction to Extended Producer Responsibility, National Centre for Design at RMIT, August 1998 
Gertsakis J, Morelli N \& Ryan C (2000), Industrial Ecology and extended producer responsibility, Chapter 42 in A handbook of Industrial Ecology, Elgar E, Cheltenham 2000, pp 521-529

Halliday S V (2002) Consuming and Consumed, Consumption, Christianity and Creation, Seminar on $5^{\text {th }}$ July 2002, Centre for Sustainable Consumption, Sheffield Hallam University.

HM Treasury (2002), Tax and the environment: using economic instruments, HMSO, UK

ICER (2000), UK Status Report on Waste from Electrical and Electronic Equipment, Industry Council for Electrical and Electronic Equipment Recycling (ICER), London, 2000

Ijomah W et al (1999), Remanufacturing: Evidence of environmentally conscious business practice in the $U K, 2^{\text {nd }}$ Int. Working Seminar on Re-use. March 1-3, TU Eindhoven, 1999

Ijomah W (2002), A model-based definition of the generic remanufacturing business process Doctoral thesis, University of Plymouth, UK

Jacobs, (1991) The Green economy: environment, sustainable development and the politics of the future London: Pluto Press, 1991, pp 110-116

Kerr W \& Ryan C (2001), Eco-efficiency gains from remanufacturing. A case study of photocopier remanufacturing at Fuji Xerox Australia, Journal of Cleaner Production, Vol. 9, pp 75-81, 2001

King AM \& Burgess SC (2004), Understanding the barriers to remanufacturing: restoring used products to a like-new condition. Submitted to the Design Studies Journal.

Lund R (1985), Remanufacturing: The experience of the United States and implications for developing countries. UNDP Project Management Report No 2. World Bank Technical Paper No 31, pp 24-34.

Meadows D H et al (1992) Beyond the Limits: global collapse, or a sustainable future? London, Earthscan

NERC (1999), Recycling and the Environment: Facts about recycling in New York, Northeast Recycling Council, August 1999, http://www.nerc.org/fsheets/ny.html (visited on 21 November, 2003)

NRC (1999), Buy Recycled Guidebook, http://www.nrc-recycle.org/brba/Buy_Recycled_Guidebook.pdf [21st November 2003]

OECD (2001), Environmental Outlook Report 2001, http://www.oecd.org/dataoecd/51/6/2088589.pdf $\left[10^{\text {th }}\right.$ October, 2003]

Ogilvie S M (1992) A review of the environmental impact of recycling, Warren Spring Laboratory, Stevenage UK. 
Packard V (1963) The Waste Makers, Longmans, 1961, pp 68-77

Parker D (2003), Remanufacturing in the UK: A significant contributor to sustainable development? Oakdene Hollins Ltd, Aylesbury UK, 2003

PriceWaterhouseCoopers (2002) Environmental Life Cycle Assessment and Financial Life Cycle Analysis of the WEEE Directive and its implications for the UK. A study produced for the UK Department of Trade and Industry, 2002, p42.

Renew (2004) Sales practice of Renew Trust UK, Intermediate Labour Organisation that reconditions old electrical products, http://www.renewtrust.co.uk/sales.htm [10th February 2004]

Stahel W R (1994) The Utilization-focused Service Economy: Resource Efficiency and Product Life Extension, in The Greening of Industrial Ecosystems, National Academy Press, 1994, pp 178-190

Tilton J E (2003), On Borrowed Time? Assessing the threat of mineral depletion, Resources for the Future, 2003, pp 101-123

Xerox (2003), Environment, Health \& Safety Progress Report 2003, Xerox. www.xerox.com [12 November 2003]

Villalba G., Segarra M., Fernández A. I., Chimenos J. M. \& Espiell F. (2002), A proposal to quantify the recyclability of materials, Resources, Conservation and Recycling, Vol. 37, Issue 1, 2002, pp 39-53 


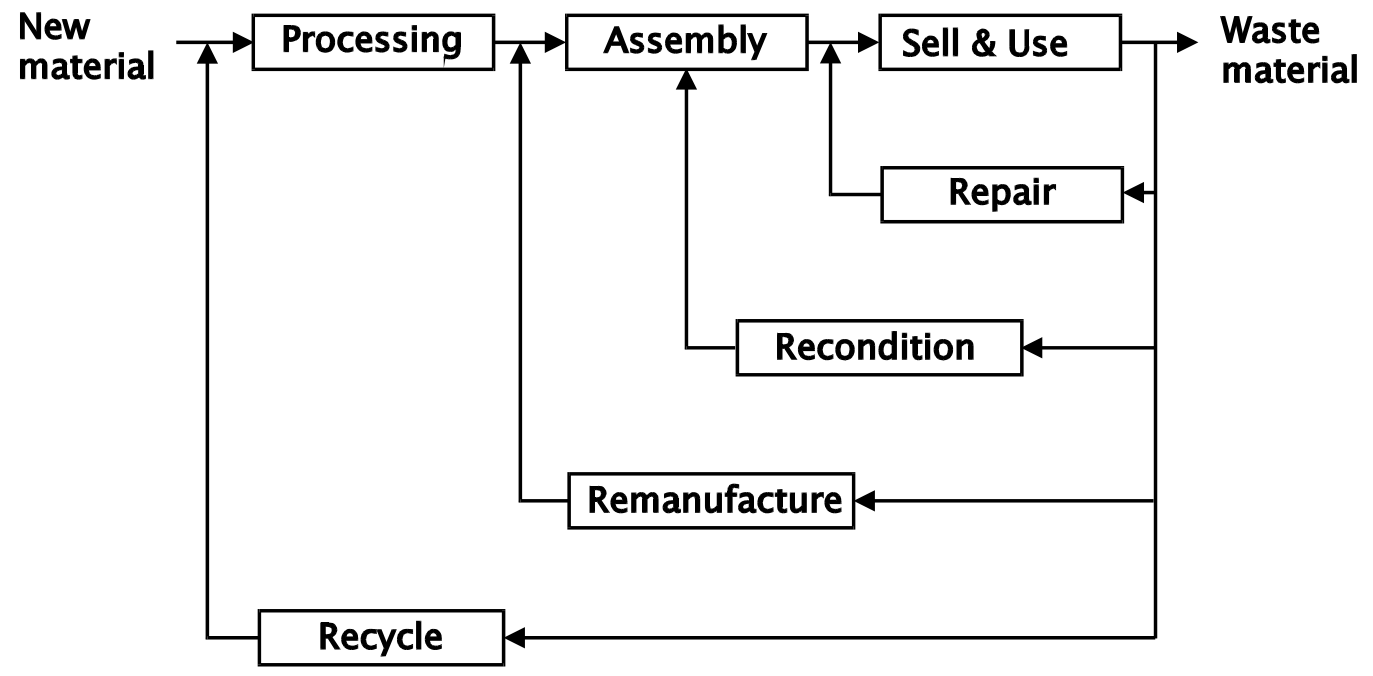

Figure 1: Closed loop design through repair, remanufacturing or recycling 


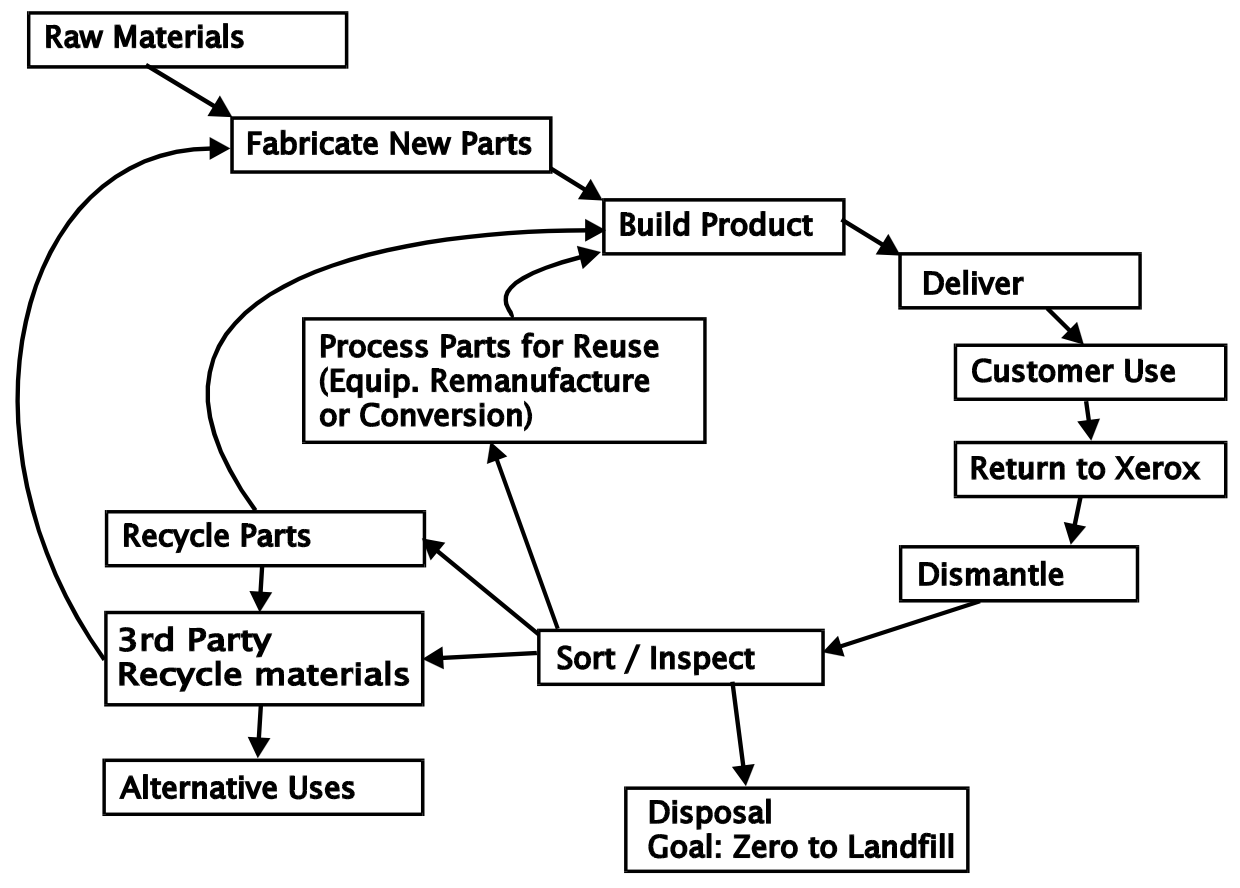

Figure 2: Xerox's equipment recovery \& parts reuse/recycle process (Xerox, 2003) 




Figure 3: The hierarchy of secondary market production processes (Ijomah W, 2002) 




Figure 4; Self-replenishing loops: $1=$ reuse, $2=$ repair, $3=$ remanufacture, $4=$ recycle 